\title{
Multiple regression models for the prediction of the maximum obtainable thermal efficiency of organic Rankine cycles
}

\author{
Larsen, Ulrik; Pierobon, Leonardo; Wronski, Jorrit; Haglind, Fredrik
}

Published in:

Energy

Link to article, DOI:

10.1016/j.energy.2013.10.026

Publication date:

2014

Link back to DTU Orbit

Citation (APA):

Larsen, U., Pierobon, L., Wronski, J., \& Haglind, F. (2014). Multiple regression models for the prediction of the maximum obtainable thermal efficiency of organic Rankine cycles. Energy, 65(1), 503-510.

https://doi.org/10.1016/j.energy.2013.10.026

\section{General rights}

Copyright and moral rights for the publications made accessible in the public portal are retained by the authors and/or other copyright owners and it is a condition of accessing publications that users recognise and abide by the legal requirements associated with these rights.

- Users may download and print one copy of any publication from the public portal for the purpose of private study or research.

- You may not further distribute the material or use it for any profit-making activity or commercial gain

- You may freely distribute the URL identifying the publication in the public portal

If you believe that this document breaches copyright please contact us providing details, and we will remove access to the work immediately and investigate your claim. 


\title{
Multiple regression models for the prediction of the maximum obtainable thermal efficiency of organic Rankine cycles
}

\author{
Ulrik Larsen*, Leonardo Pierobon, Jorrit Wronski, Fredrik Haglind \\ The Technical University of Denmark, Department of Mechanical Engineering, Section of Thermal Energy, \\ Building 403, Nils Koppels Allé, 2800 Kongens Lyngby, Denmark
}

\begin{abstract}
Much attention is focused on increasing the energy efficiency to decrease fuel costs and $\mathrm{CO}_{2}$ emissions throughout industrial sectors. The organic Rankine cycle (ORC) is a relatively simple but efficient process that can be used for this purpose by converting low and medium temperature waste heat to power. In this study we propose four linear regression models to predict the maximum obtainable thermal efficiency for simple and recuperated ORCs. A previously derived methodology is able to determine the maximum thermal efficiency among many combinations of fluids and processes, given the boundary conditions of the process. Hundreds of optimised cases with varied design parameters are used as observations in four multiple regression analyses. We analyse the model assumptions, prediction abilities and extrapolations, and compare the results with recent studies in the literature. The models are in agreement with the literature, and they present an opportunity for accurate prediction of the potential of an ORC to convert heat sources with temperatures from 80 to $360^{\circ} \mathrm{C}$, without detailed knowledge or need for simulation of the process.
\end{abstract}

Keywords: Organic Rankine cycle, Performance prediction, Waste heat recovery, Multiple regression analysis

\section{Introduction}

With the continued and widespread focus on improvements of the energy efficiency in many types of industrial processes, waste heat recovery (WHR) systems are becoming increasingly relevant. The organic Rankine cycle (ORC) is a promising technology which is able to convert waste heat into power and electricity without fuel input and $\mathrm{CO}_{2}$ emissions, besides those associated with the plant construction. The process is relatively simple, compared to the steam Rankine cycle [1], and it can obtain high conversion efficiencies of low temperature heat compared to competing technologies.

The main reason for the relatively high efficiency of the ORC is that the working fluid can be selected to suit the heat source thermodynamically. Hence, a much studied subject and a non-trivial task is the selection of the most suitable working fluid. Due to

\footnotetext{
${ }^{*}$ Corresponding author. Tel.: +4553250303

Email address: ular@mek.dtu.dk (Ulrik Larsen)
}

the large number of potential fluid candidates, it is a relatively laborious task to determine the maximum potential efficiency when applying an ORC to utilise a given (waste) heat source. The main reason is that finding the maximum potential of the ORC involves the simultaneous selection of the optimum fluid, process parameters and process layout.

The use of various working fluids have been studied in the literature and correlations have been proposed for the prediction of process efficiencies. Liu et al. [2] proposed an equation for the prediction of the thermal efficiency of an ORC plant using isentropic fluids, based on the evaporation, condensing and critical temperatures of the working fluid. The equation was shown to be in reasonable agreement with a limited number of model results. Teng et al. [3] derived a very similar relation in 2007 [3]. Recently, Wang et al. [4] also described a similar correlation. Kuo et al. [5] presented a thorough study of the Jacob number which was shown to be very useful for the prediction of thermal efficiency. Additionally, a new figure of merit was able to extend the use of the Jacob 


\section{Nomenclature}

\section{Acronyms}

GA Genetic algorithm

ORC Organic Rankine cycle

WHR Waste heat recovery

\section{Greek Symbols}

$\beta$ Regression coefficient

$\Delta$ Difference

$\eta$ Efficiency

\section{Symbols}

$e$ Residual

$T$ Temperature $\left({ }^{\circ} \mathrm{C}\right)$

y Response variable

$z$ Predictor variable

\author{
Subscripts \\ e Expander \\ hs Heat source \\ i Inlet condition \\ $\mathrm{j}$ Number of response \\ $\max$ Maximum \\ o Outlet condition \\ p Polytropic \\ pp Pinch point \\ $r$ Number of predictor variables \\ s Sink \\ t Trilateral \\ th Thermal
}

number, to make predictions at various condensation and evaporation temperatures. Wang et al. [6] later included the Jacob number in two prediction models: one for thermal efficiency and one for exergetic efficiency.

Common for the mentioned correlations is that the prediction of the efficiency is based on fluid properties, which are specific for a given fluid candidate. While being very useful, the correlations do not provide the knowledge of what could maximally be obtained from a given heat source when using the best fluid. The Carnot efficiency can provide the idealistic maximum for a constant temperature heat source, and the Trilateral cycle efficiency equation can be used for a non-isothermal heat source [7]. The Trilateral efficiency is derived from the Carnot cycle efficiency and provides an idealistic estimate where the heat source is utilised fully; however, in many cases not all the heat available can be used. An example is when the heat is supplied by exhaust gas where condensation of sulphuric acid in heat exchangers must be avoided, and another is when the cooler part of a heat source is needed for heating purposes.

Previous work by the present authors [8] derived a methodology useful for determining the maximum obtainable thermal efficiency, given the heat source and other process parameters, while considering a wide range of working fluids, pressures and process layouts. It was concluded that the maximum thermal efficiency obtainable across the solution domain, is very strongly correlated with the heat source inlet temperature. Furthermore, it was concluded that the optimum working fluid depended upon the heat source inlet temperature, a finding which has also been obtained by Wang et al. 2013 [6] among others.

In the present study we present four correlations which can be used as models to predict with good accuracy the maximum obtainable thermal efficiency of simple and recuperated ORCs. The maximum potential performance of many waste heat recovery systems can thus be predicted using only a few key design parameters and without the need of knowledge of working fluid properties and their use in ORCs. Furthermore, the influence of each of the design parameters can be straightforward evaluated using the proposed models.

The correlations are based on multiple regression analyses of the results in a large number of optimisation cases. The optimisations cover cases with and without recuperation, sub- and supercritical pressure processes and 109 possible fluid candidates (wet, dry and isentropic) and the optimisation methodology (previously derived [8]) allowed for the simultaneous optimisation of the process, fluid and process parameters.

The four correlations cover a heat source temperature range from 80 to $360^{\circ} \mathrm{C}$. The parameters in the models are the heat source inlet and outlet temperatures, the expander efficiency, the condensation tem- 
perature and the minimum allowed temperature difference in the boiler and recuperator.

We believe that the models can help increase the accessibility of the ORC technology by significantly reducing the resources needed to evaluate the potential of its implementation. As an example, the models can be used in preliminary studies of combined cycles and other integrated energy systems.

A brief description of the applied modelling and optimisation methodology is provided in section 2, which also includes an outline of the method used in the regressions analysis. Section 3 presents a statistical analysis of the results including the four regression models. We present a discussion of the results in section 4 , and we discuss how the findings relate to results found in the literature as well as the limitations of the model.

\section{Methodology}

This section provides a brief outline of the previously derived methodology, which was applied to obtain the data on which the regression model was built. The governing equations are described in detail in previous work by the authors [8]. Also provided are the relevant statistical aspects for obtaining the regression models and for their evaluation.

The ORC model was built with Matlab R2010b software [9] using NIST Refprop [10] equations of state to resolve the thermodynamic states in the process.

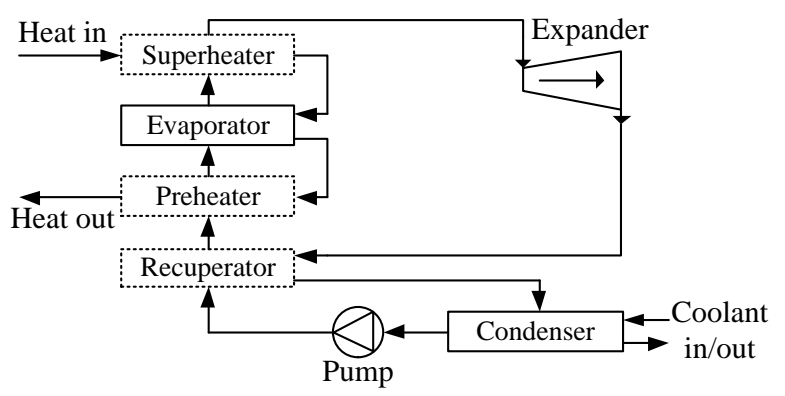

Figure 1: Sketch of the ORC

The model was made for optimisation purposes, such that all kinds of fluids can be included in the optimisation search. Also, both sub- and supercritical evaporation pressure levels can be included, and the process layouts available with the model include ORCs with and without a preheater, recuperator and superheater (in any combination). Figure 1 is a sketch of the process model where the optional components are indicated using dotted lines. Hence, this ORC modelling methodology aims at finding the maximum obtainable efficiency among a wide range of options.

The boiler heat exchangers were modelled using a discretisation which enables the inclusion of processes with supercritical pressures as well as fluid mixtures (although we have not yet considered mixtures) for which the minimum temperature approach cannot be predicted a priori.

The expander was modelled using a polytropic efficiency. This was chosen because the optimisation was employed at a wide range of pressures and since it was desirable to have a comparable level of technology and cost of the expander in all cases. Since the influence of the pump efficiency on the overall process is relatively small, the pump was modelled using an isentropic and not a polytropic efficiency to reduce computation time.

Generally the modelling was done under the assumptions of steady-state, homogeneous flow, homogeneous temperatures and pressures. No pressure or heat losses were accounted for. The minimum allowed vapour quality at any point in the expander was set to $85 \%$ in order to accommodate wet fluids. The pump efficiency was set to $70 \%$.

Two algorithms were used for optimisation: a Matlab function fminbnd, which uses the Golden section search method and the Parabolic interpolation method [9], was used to optimise the superheater approach. A genetic algorithm (GA) [11] was used to optimise the working fluid and boiler pressure, and in each individual simulation in the GA optimisation, the superheater approach was optimised. The upper limit for the boiler pressure was set to 120 bar. In principle, the GA would be able also to optimise the superheater approach, but the mentioned approach was found to be faster. Table 1 presents the parameters used for the GA optimisation.

\begin{tabular}{rr} 
Table 1: Genetic algorithm parameters \\
\hline Generations & 15 \\
Sub-populations & 15 \\
Individuals & 70 \\
Cross-over rate & 1 \\
Generation gap & 0.8 \\
Mutation rate & 0.5 \\
Insertion rate & 0.9 \\
Migration rate & 0.2 \\
Generations between migrations & 2
\end{tabular}




\subsection{Regression analysis}

In order to obtain reasonable accuracy for the models, two low temperature models were derived covering the heat source inlet temperature range $80-180^{\circ} \mathrm{C}$ : one for simple (no recuperation) ORCs and one for recuperated (whenever advantageous) ORCs, and similarly, two high temperature models covering the heat source inlet temperature range $180-360^{\circ} \mathrm{C}$.

The models were derived based on a number of random observations of the model results: for the high temperature cases 100 and for the low temperature cases 85 . The lower number is due to the lower number of parameters in the low temperature models.

\begin{tabular}{|c|c|c|}
\hline Model & Low & High \\
\hline$T_{h s, i}\left({ }^{\circ} \mathrm{C}\right)$ & 80 to 180 & 180 to 360 \\
\hline$T_{h s, o}\left({ }^{\circ} \mathrm{C}\right)$ & 50 to 80 & 60 to 160 \\
\hline$\eta_{p, e}(\%)$ & 60 to 80 & 60 to 80 \\
\hline$T_{c}\left({ }^{\circ} \mathrm{C}\right)$ & 25 (fixed) & 15 to 50 \\
\hline$\Delta T_{p p}\left({ }^{\circ} \mathrm{C}\right)$ & 5 (fixed) & 5 to 20 \\
\hline
\end{tabular}

The input parameters for the modelled results were varied randomly within the intervals shown in Table 2 , and for each case the maximum thermal efficiency was found. There seems to be a general consensus within the relevant literature that these are the key process parameters, which were investigated most recently by Wang et al. [12]. $T$ is temperature, $\eta$ is efficiency, subscripts $h s, i, o, p, e, c$ and $p p$ are short for the heat source inlet and outlet conditions, polytropic, expander, condensation and pinch point, respectively.

A linear multiple regression model may be represented by the following equation:

$$
y_{j}=\beta_{0}+\beta_{1} z_{j 1}+\beta_{2} z_{j 2}+\ldots+\beta_{r} z_{j r}+e_{j}
$$

where $y_{j}$ is the $j$ th response to be predicted using the (predictor) variables, $z_{j 1}$ to $z_{j r}$ given as input. $r$ is the number of predictor variables and $\beta$ the regression coefficients. $e_{j}$ is the $j$ th residual or error between the predicted response and the observation. The observations are the optimised thermal efficiencies.

The least squares principle was used to determine the regression coefficients. The method determines the coefficients that produce the minimum sum of squared residual values, i.e. the best fitted regression line. Non-linear models were also investigated, but the linear model showed to provide the best fit with the observed data in all four cases.
In order to evaluate the regression models statistically, the following assumptions regarding the residuals (or standardised residuals) were verified as according to Larsen et al. [13]:

1. The mean value of residuals $\left(e_{j}\right)$ is equal to zero.

2. The residuals can be plotted as a normal distribution.

3. The residuals have constant variance (homoscedasticity).

4. The residuals are independent (or random), i.e. there is no correlation with regression coefficients or the response.

The first assumption is easily verified, while the remaining are checked using plots of the standardised residuals. If assumption (2) is correct, a normal probability plot of the standardized residuals should produce a straight line. Scatter plots showing the relationship between the standardised residuals and the predicted values can be used to evaluate assumptions (3) and (4). If the residuals are evenly and randomly distributed around zero, then the assumptions hold true. These four points are verified in the next section.

\section{Results}

In the following, the models for the ORCs with a recuperator allowed, but not necessarily applied, are called ORCs. The models for the ORCs without a recuperator are called simple ORCs. Next, the models and the regression analyses results are presented including results of testing the model assumptions.

\subsection{Regression models}

Table 3 presents the regression coefficients and standard errors for both the low temperature models. Each of the coefficients indicates the influence of each predictor variable $\left(T_{h s, i}, T_{h s, o}\right.$ and $\left.\eta_{p, e}\right)$ on the thermal efficiency. For example, the coefficient for the heat source inlet temperature is lower for the simple ORC, indicating that the benefit of increasing the heat source inlet temperature is relatively smaller compared to the ORC. The standard errors of each of the coefficients are the margins for the model output to remain within a $95 \%$ confidence interval of the observed (simulated) values. They are all seen to be minor compared to the coefficients. 
Table 3: Model coefficients and statistics for low temperature heat sources

\begin{tabular}{rrrrr}
\hline & \multicolumn{2}{c}{ ORC } & \multicolumn{2}{c}{ Simple ORC } \\
\hline & Coeff. & Std. error & Coeff. & Std. error \\
\hline Constant $\left(\beta_{0}\right)$ & -16.32 & 0.5056 & -14.92 & 0.9034 \\
$T_{h s, i}$ & 0.08402 & 0.00129 & 0.07339 & 0.001718 \\
$T_{h s, o}$ & 0.08349 & 0.0043 & 0.08363 & 0.006474 \\
$\eta_{p, e}$ & 0.1583 & 0.00536 & 0.1464 & 0.009767 \\
\hline
\end{tabular}

Table 4 presents the regression model coefficients and the associated statistics for the high temperature models. It is seen that the influence of $T_{h s, i}$ on the model output (thermal efficiency) is again smaller for the simple ORC model. This is also the case for the other variables $T_{h s, o}, T_{c}$ and $\Delta T_{p p}$, except the expander efficiency. This suggests that the expander efficiency is more influential on the simple ORC efficiency.

Table 4: Model coefficients and statistics for high temperature heat sources

\begin{tabular}{rrrrr}
\hline & \multicolumn{2}{c}{ ORC } & \multicolumn{2}{c}{ Simple ORC } \\
\hline & \multicolumn{1}{c}{ Coeff. } & \multicolumn{1}{c}{ Std. error } & Coeff. & Std. error \\
\hline Constant $\left(\beta_{0}\right)$ & -12.76 & 0.5377 & -12.33 & 1.100 \\
$T_{h s, i}$ & 0.06428 & 0.0007 & 0.05858 & 0.001458 \\
$T_{h s, o}$ & 0.05897 & 0.0012 & 0.03350 & 0.00259 \\
$\eta_{p, e}$ & 0.2576 & 0.00604 & 0.2666 & 0.0130 \\
$T_{c}$ & -0.1727 & 0.0033 & -0.1552 & 0.00790 \\
$\Delta T_{p p}$ & -0.1556 & 0.0081 & -0.0810 & 0.01832 \\
\hline
\end{tabular}

Consequently, the regression models for predicting the maximum obtainable thermal efficiencies of the ORC are:

$$
\begin{aligned}
& \eta_{t h, \max }=-16.32+0.08402 T_{h s, i}+0.08349 T_{h s, o} \\
& +0.1583 \eta_{p, e} \\
& \eta_{t h, \max }=-14.92+0.07339 T_{h s, i}+0.08363 T_{h s, o} \\
& \quad+0.1464 \eta_{p, e} \\
& \eta_{t h, \max }=-12.76+0.06428 T_{h s, i}+0.05897 T_{h s, o} \\
& \quad+0.2576 \eta_{p, e}-0.1727 T_{c}-0.1556 \Delta T_{p p} \\
& \eta_{t h, \max }=-12.33+0.05858 T_{h s, i}+0.03350 T_{h s, o} \\
& \quad+0.2666 \eta_{p, e}-0.1552 T_{c}-0.0810 \Delta T_{p p}
\end{aligned}
$$

where Eq. 2 is for ORCs with heat sources with an inlet temperature of $80-180^{\circ} \mathrm{C}$, and Eq. 3 predicts the maximum performance of simple ORCs within the same temperature range. Temperatures are given in degrees Celsius and the efficiencies in percent. Subscripts th and $\max$ are short for thermal and maxi- mum, respectively. Equations 4 and 5 yield predictions for heat sources from $180-360^{\circ} \mathrm{C}$ for ORCs and simple ORCs, respectively.

In order to obtain reasonable accuracy, the number of parameters in the low temperature models is limited to the three shown in Eqs. 2 and 3. It should thus be noted that the low temperature cases are only valid for a condensing temperature of $25^{\circ} \mathrm{C}$ and a $\Delta T_{p p}$ of $5^{\circ} \mathrm{C}$. However, the high temperature models can maintain better prediction accuracies; hence, the models include the condensing temperature and $\Delta T_{p p}$ parameters as well.

\subsection{Statistical evaluation}

The regression statistics are listed in Table 5. The adjusted $R^{2}$ value (coefficient of determination) takes into account the size of the data set and the number of predictor variables [14], and for all the models it is seen to approach unity. The statistically strongest model is the high temperature ORC; however, all the models are statistically strong judging from the Fsignificances.

Table 5: Regression statistics

\begin{tabular}{rrrr}
\hline & Adjusted $R^{2}$ & Std. error & F-significance \\
\hline ORC, low & 0.961 & 0.343 & $6.4^{*} 10^{-91}$ \\
Simple ORC, low & 0.966 & 0.500 & $9.0^{*} 10^{-58}$ \\
ORC, high & 0.994 & 0.353 & $3.5^{*} 10^{-104}$ \\
Simple ORC, high & 0.965 & 0.694 & $3.6^{*} 10^{-57}$ \\
\hline
\end{tabular}

Additionally, the P-values (not listed) for each of the coefficients represent the probability of each of the predictor variables being insignificant for the model result. For all the coefficients in the four models, the $\mathrm{P}$-values are in the range of $1^{*} 10^{-30}$ to $1^{*} 10^{-100}$, i.e. it is certain that the variables are important for the predicted maximum thermal efficiency, as should be expected. One exception is the $\Delta T_{p p}$ variable in the high temperature simple ORC model which has a $\mathrm{P}$ significance of $3^{*} 10^{-5}$.

\subsection{Verification of model assumptions}

Due to the comparable results, verification is omitted for models other than the high temperature ORC model. However, a brief discussion illustrates the outcome of these additional verifications.

For all four models, the mean value of the residuals is about $1^{*} 10^{-15}$, i.e. very close to zero; hence, this first assumption is verified. The second assumption to be verified is that the residuals present a normal 
distribution. Figure 2 shows how this is true to a relatively high degree, since the residuals form a fairly straight line, as the linear trend line also drawn has a $R^{2}$ value of $98.5 \%$. Similarly, when plotting the residuals of the data for the other three models, the $R^{2}$ values are $99.1 \%$ and $98.3 \%$ for the low temperature ORC and simple ORC models, respectively, and $97.3 \%$ for the simple ORC high temperature model.

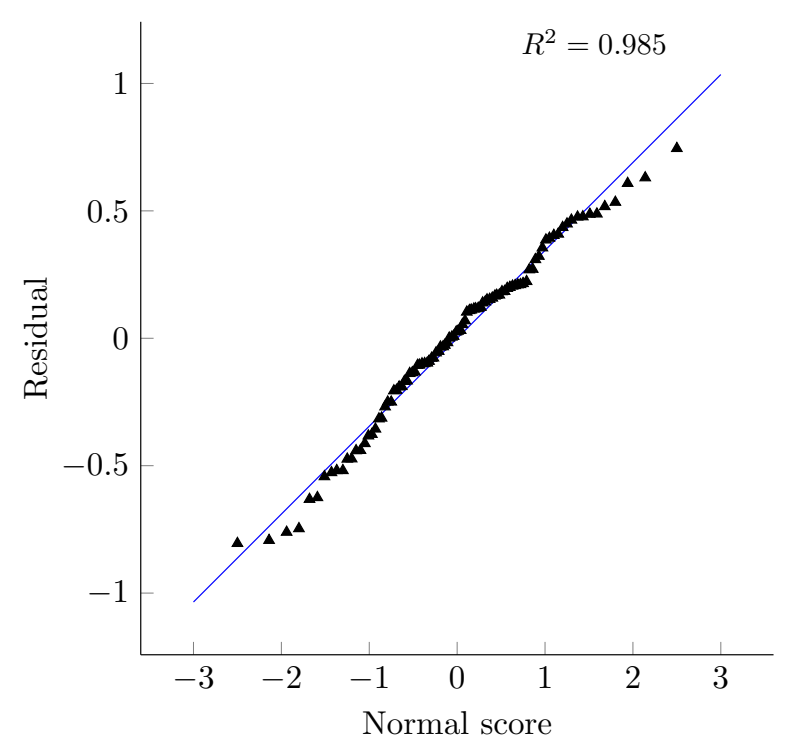

Figure 2: Normal probability plot

Figure 3 (a-f) depicts the residuals plotted against each of the five predictor variables and the predicted thermal efficiency. The figure shows how all five variables have been properly varied within their respective ranges. No specific pattern formed by the residuals can be observed, thus verifying the assumptions of constant variance and independence of the residuals. When examining the residuals for the other three models very similar pictures are seen.

\subsection{Prediction ability}

As was seen in Table 5, the standard error for all the models is relatively small compared to the ranges of thermal efficiencies. This is illustrated in Fig. 4, where the predicted values for the high temperature ORC model are plotted against the observed (simulated). It is evident that the predicted maximum obtainable thermal efficiencies are very close to the simulated and optimised values.

Similarly, Fig. 5 presents the predicted against the observed values for the low temperature ORC model. The prediction is seen to be not as good with this model compared to the high temperature model. For

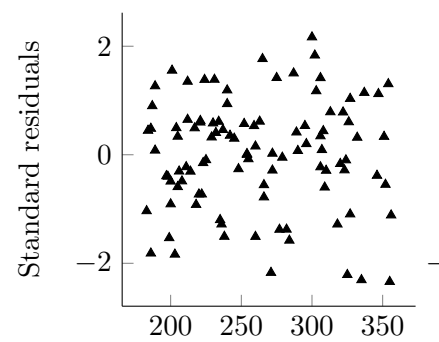

(a) $T_{h s, i}\left({ }^{\circ} \mathrm{C}\right)$

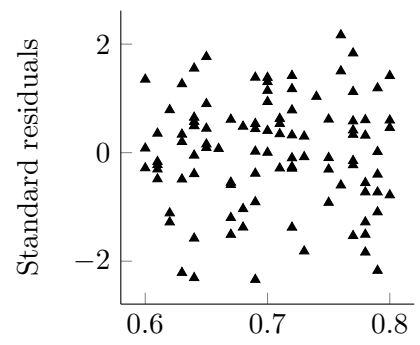

(c) $\eta_{p, e}$

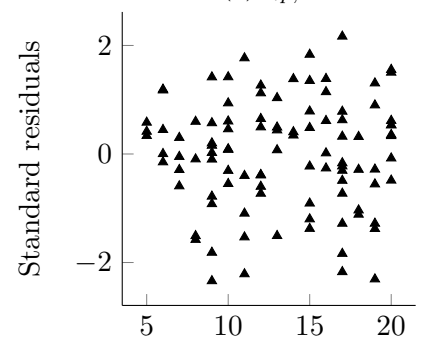

(e) $\Delta T_{p p}\left({ }^{\circ} \mathrm{C}\right)$

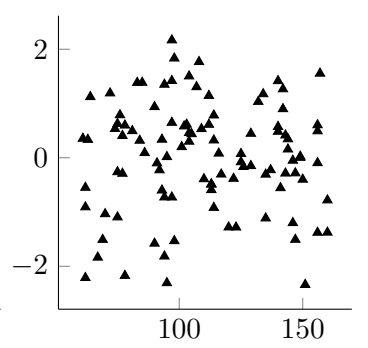

(b) $T_{h s, o}\left({ }^{\circ} \mathrm{C}\right)$

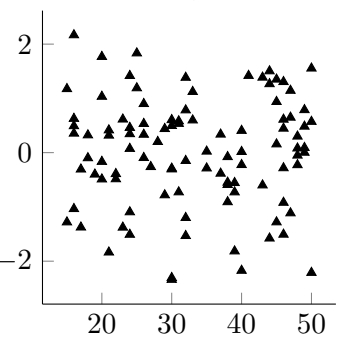

(d) $T_{c}\left({ }^{\circ} \mathrm{C}\right)$

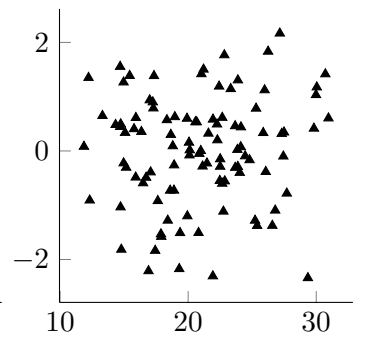

(f) $\eta_{t h}(\%)$
Figure 3: Plots of residuals

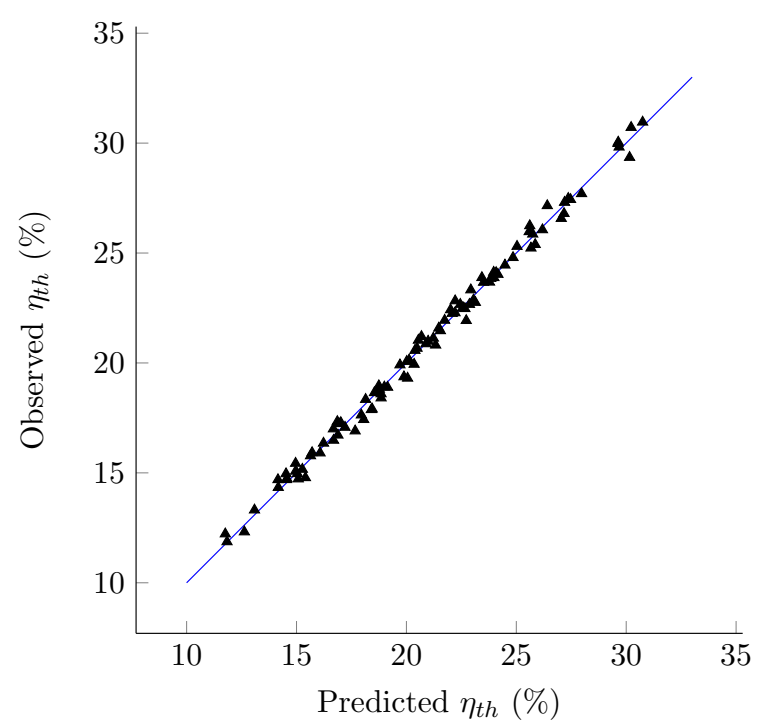

Figure 4: Prediction ability for the high temperature ORC model 
the simple ORC models, the predictions show a very similar picture as in Fig. 5.

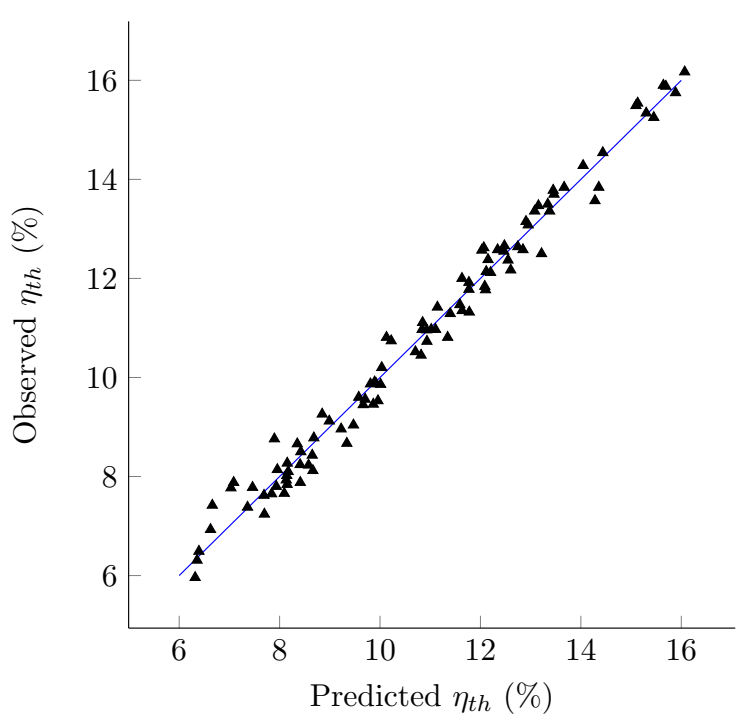

Figure 5: Prediction ability for the low temperature ORC model

\subsection{Extrapolation}

Model extrapolation outside the scope of the observed values (see Table 2) will result in predictions which are increasingly inaccurate. Figure 6 presents predictions using the low and high temperature models with extrapolations. In both cases shown, the heat source outlet temperature is kept at $60^{\circ} \mathrm{C}$, the expander efficiency at $70 \%$, the condensation temperature at $25^{\circ} \mathrm{C}$ and the $\Delta T_{p p}$ at $5^{\circ} \mathrm{C}$. The figure illustrates how the two models diverge from each other when varying the heat source inlet temperature beyond the observation data ranges. The divergence is seen to be significant compared to the predicted values. Similar trends are present when extrapolating the other predictor variables.

\subsection{Comparison with the theoretical maximum}

The Trilateral cycle efficiency, which is derived from the Carnot cycle efficiency, can be used as a measure of the maximum obtainable efficiency for a non-isothermal heat source which is cooled to the condensing temperature [7]. In cases where the heat source is not cooled to that extent, the efficiency is higher due to the higher average temperature of the heat added to the process. Assuming that the heat source is cooled by the working fluid while describing a linear function, the Trilateral efficiency $\left(\eta_{t}\right)$ can be described by the following equation:

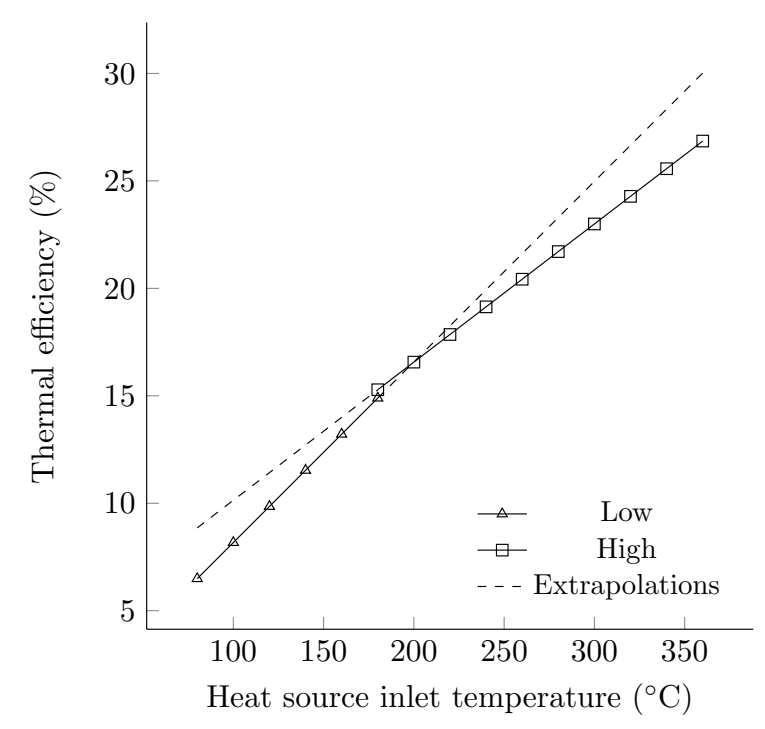

Figure 6: Extrapolation of the ORC regression models

$$
\eta_{t}=1-\frac{T_{s} \ln \left(T_{h s} / T_{s}\right)}{T_{h s}-T_{s}}
$$

where $T_{s}$ is the sink temperature. Figure 7 presents a comparison of the maximum obtainable thermal efficiencies for the ORC, the simple ORC and the Trilateral cycle. The four regression models have been combined to cover the temperature range from 80 to $360^{\circ} \mathrm{C}$. The heat source outlet temperature is kept at $60^{\circ} \mathrm{C}$, the expander efficiency at $70 \%$, the condensation temperature at $25^{\circ} \mathrm{C}$ and the $\Delta T_{p p}$ at $5^{\circ} \mathrm{C}$, in order to be able to connect the low and high temperature models for each process.

It is seen that the difference between the ORC and the simple ORC is relatively small. It should be noted that with values of $T_{h s, o}$ higher than the $60^{\circ} \mathrm{C}$ used for the figure, the predicted efficiency can easily exceed the Trilateral efficiency for any given heat source inlet temperature.

A sudden change at around $180^{\circ} \mathrm{C}$ is seen in the figure for the simple ORC model. This is where the low and high temperature models meet, and as seen, it is not given that the two models coincide at their respective end points. This sudden change can be seen as an indicator of the size of the inaccuracy of the models.

\subsection{Optimum working fluids}

For coherence reasons Figs. 8 and 9 provide information on the working fluids leading to the results on 


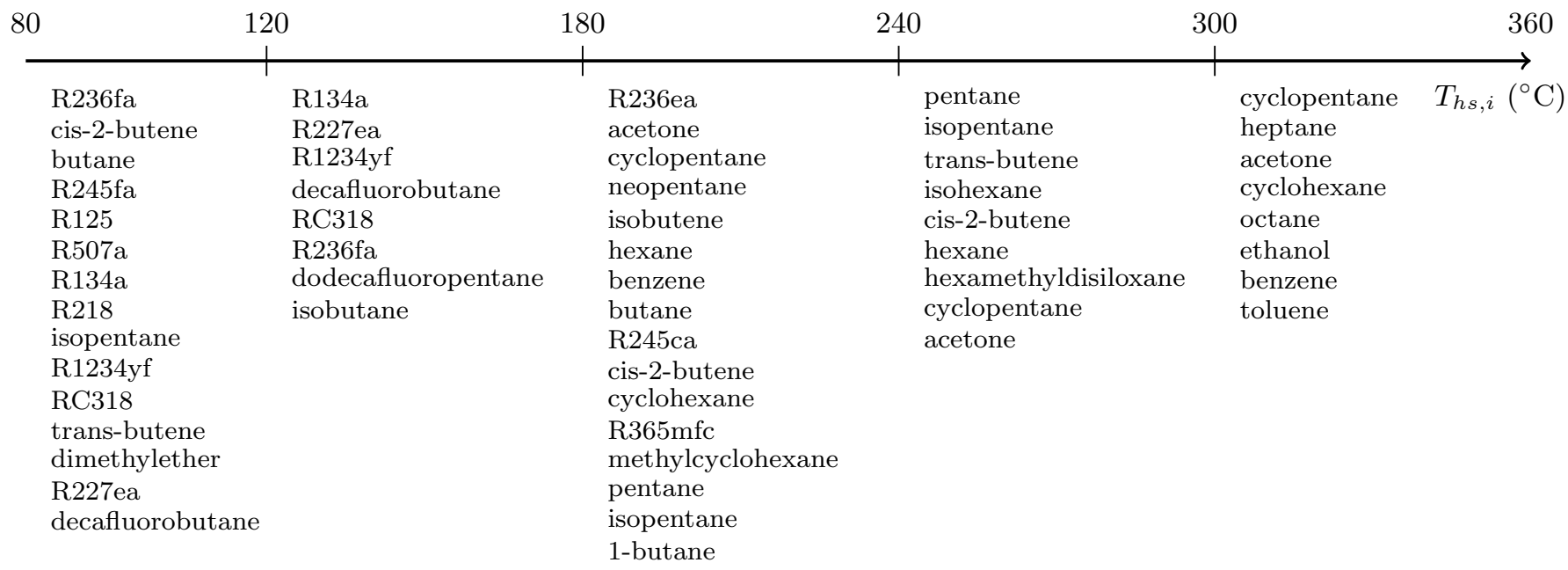

Figure 8: Working fluids for the ORC

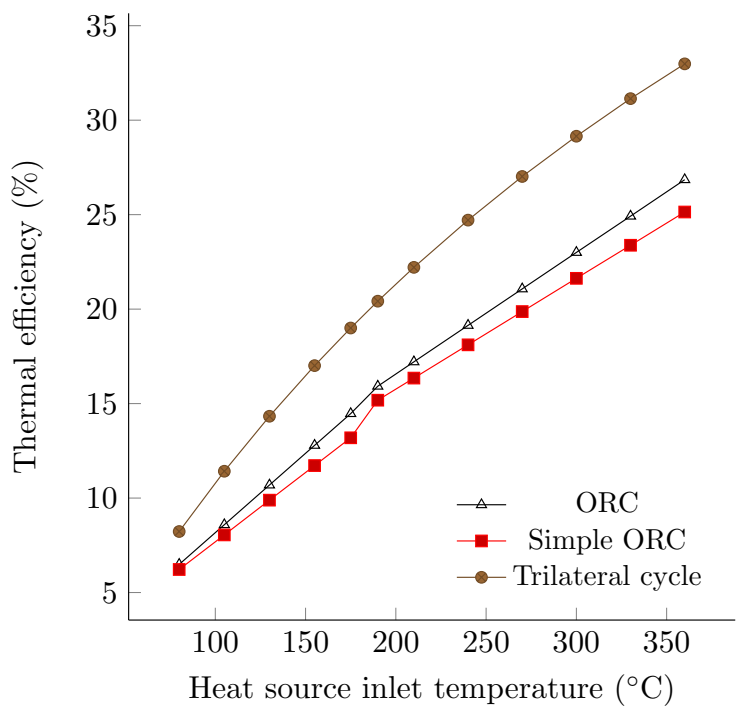

Figure 7: Comparison with the Trilateral cycle efficiency which the regression analyses were made. The figures are made with inspiration from the work of Wang et al. [6]. The working fluids are the ones leading to the maximum efficiency from the ORC given the input parameters. The fluids are aligned from left to right with increasing heat source inlet temperature, within the intervals shown. The other parameters $\left(T_{h s, o}\right.$, $\eta_{p, e}, T_{c}$ and $\left.T_{p p}\right)$ are randomly distributed within the intervals as shown in Fig. 3.

The fluids are also aligned in the columns from the top down with increasing $T_{h s, i}$. For example, Fig. 8 shows that with the lowest value of $T_{h s, i}\left(80^{\circ} \mathrm{C}\right)$, the optimum working fluid is R236fa. As $T_{h s, i}$ gets closer to $120^{\circ} \mathrm{C}$, the optimum working fluids are cis2-butene, butane, R245fa, etc. It is noted, however, that many of the fluids are optimum at more than one heat source inlet temperature. This is because the optimum fluid is also dependent on the other parameters.

Figure 9 presents the optimum working fluids for the simple ORC. It is seen that the fluids are not the same as in Fig. 8. Moreover, the number of fluids in each column is smaller in comparison. This means that for the simple ORC fewer fluids dominate as the optimum fluids, across the temperature range.

In both Figs. 8 and 9 acetone is present in the temperature range 180 to $360^{\circ} \mathrm{C}$. For the $\mathrm{ORC}$, the refrigerants and alkanes (dry fluids) dominate the figure, while ammonia and ethanol (wet fluids) are frequently the optimum fluid for the simple ORC. 


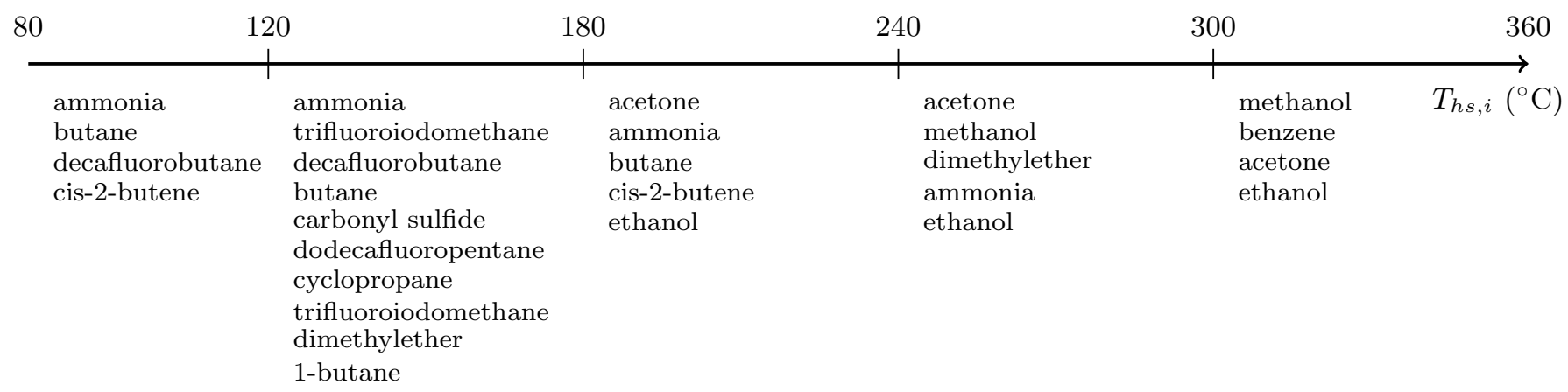

Figure 9: Working fluids for the simple ORC

\section{Discussion}

Here we will discuss the limitations associated with the proposed regression models and provide points of comparison with recent literature.

\subsection{Limitations}

However useful the proposed models may be, it is important to note the following limitations. The work presented relies on the accuracy of the thermodynamic states provided by the NIST Refprop software. However, in the process of constructing the equations of state, the goal is to produce the best fit, i.e. the model has the least average deviation from measured data. Hence, it can be assumed that the errors are randomly distributed, and consequently the effects of the errors may be somewhat balanced out. While further studies should be made to confirm this, Thorin et al. [15] investigated the effect of using different equations of state in power cycles and found that they resulted in very similar process efficiencies.

It is required in the linear regression analysis that the errors of the models are evenly and randomly distributed as shown in Fig. 3. Consequently, the relative error increases with decreasing predicted efficiency. This is particularly relevant for the low temperature models, and consequently in this work, we have limited the models by keeping the condensing temperature and pinch point temperature differences constant. Initially we attempted to include these two variables also for the low temperature models. However, the resulting models became very inaccurate with relative errors of more than $50 \%$.

Due to the above, the efficiency of small scale ORC plants for utilising low temperature heat sources is not predicted very accurately. Additionally, for this application type, factors other than the proposed
$\left(T_{h s, i}, T_{h s, o}\right.$ and $\left.\eta_{p, e}\right)$ influence the process, as for example, the pump efficiency. Thus the low temperature models may be considered too simplified, and further studies dedicated to low temperature heat sources are therefore proposed for future work.

Another important limitation is that the models are valid only for heat sources with a relatively constant specific heat over the temperatures of the heat source from inlet to outlet. Condensing heat sources can thus not be considered and neither can combinations of more than one heat source (at different temperature levels).

The upper limit of 120 bar in the optimisation of the boiler pressure does in practice not limit the efficiency in the model results used for the regression analyses. The average optimum boiler pressure was found to be about 40 bar. However, in the simple ORC high temperature model cases, the optimum boiler pressure was generally very high (near 100 bar) when ammonia was found to be the optimum fluid. Cis-2-butene, methanol and ethanol were also found to require relatively high pressures. Due to the many available fluid alternatives, it is not expected that a significant decrease in efficiency will occur when substituting the optimum fluid with fluids having a lower optimum pressure, as was found in previous studies by the authors [8].

More important are the many other requirements for a suitable ORC working fluid. There seems to be a consensus in the literature that the following aspects are important: Global Warming Potential, Ozone Depletion Potential, chemical/thermal stability, cost, heat transfer properties, corrosiveness and levels of toxicity and fire hazards. For these reasons the proposed regression models should be seen as idealistic in the sense that they can only predict the thermodynamically calculated maximum obtainable 
efficiency. Despite the many requirements, the fluids found as optimum in the present study are commonly found in the relevant literature, as is discussed next.

\subsection{Comparison with other studies}

Bao et al. [16] recently provided an excellent literature review on ORC working fluids where the recommended fluids of various authors are listed. Among those are a number of refrigerants, which we have chosen to disregard in the present work, since they will be banned in the near future. However, fluids matching with the presently found optimum fluids and temperature levels (Figs. 8, 9) are benzene, R236ea, butane, hexane, toluene, R245ca, ammonia, R134a, ethanol and R227ea.

A number of recent studies allow for a comparison of modelled results with the regression model predictions. It is noted that the results found in these studies are not described as the maximum obtainable thermal efficiency as predicted with the regression models.

Dai et al. [17] compared the optimum performance of ten different working fluids in both the simple cycle and the recuperated cycle. With the parameters used $\left(T_{h s, i}, T_{h s, o}, \eta_{p, e}\right.$ equal to $145^{\circ} \mathrm{C}, 73^{\circ} \mathrm{C}, 85 \%$, respectively) Dai et al. [17] found an efficiency of $12.27 \%$ and the regression model finds $14.8 \%$ for a simple ORC. For a recuperated process Dai et al. [17] finds with similar data an efficiency of $12.54 \%$, while the model finds $15.5 \%$. Dai et al. [17] uses a pinch point temperature difference of $8^{\circ} \mathrm{C}$ and the regression model assumes $5^{\circ} \mathrm{C}$. Also, the expander efficiency is slightly above the valid area for the regression model. However, this does neither account for the difference nor the inherent regression model error. Instead, this difference suggests that a more efficient working fluid and/or process conditions may be available.

Walraven et al. [18] presented results which are in good agreement with the present model. The optimum efficiencies are 11.5 and $14.5 \%$ for the simple and the recuperated ORC where the regression model predicts 11.7 and $16.4 \%$, respectively. There is also good agreement when comparing the results of Trapp et al. [19]. The optimum efficiency in this study is $13.1 \%$, and the regression model predicts a maximum of $12.8 \%$ under the given conditions. The discrepancy is within the error margin of the model.

Last, it should be noted that the predicted efficiencies are well beyond what can be found in current
ORC plants, particularly for smaller scale systems. Quoilin et al. [1] states that current thermal efficiencies for ORC plants do not exceed $24 \%$.

\section{Conclusion}

Four multiple regression models have been presented. The models are able to predict the maximum obtainable thermal efficiency of ORCs utilising heat sources from $80-360^{\circ} \mathrm{C}$.

The regression models are based on results from hundreds of optimised cases using ORC models with various boundary conditions. The optimisation methodology enables the determination of the optimum process layout, working fluid and process parameters given the heat source inlet and outlet temperatures, expander efficiency, condensing temperature and minimum temperature differences in the process.

Analyses suggests that the multiple linear regression models predict the modelled results very well, and analyses of the residuals proved to verify the model assumptions.

While a number of important limitations apply, the results presented were found to be in agreement with recent literature.

To assist decision makers with little or no specific knowledge of the ORC, the regression models can, together with models for prediction of the cost of an ORC plant, provide a foundation and reduce the need for process simulation and optimisation in a preliminary evaluation of the potential.

The models allow, to some degree, a straightforward evaluation of the influence of each of the included design parameters, on the potential efficiency of the ORC given the conditions.

\section{Acknowledgements}

The authors wish to thank the Lighthouse Maritime Competence Centre located at Chalmers University of Technology in Gothenburg, Sweden, for the financial support making this study possible. Francesco Baldi is acknowledged for his valuable comments and Susan Canali is thanked for the proof reading.

\section{References}

[1] Quoilin S, Broek MVD, Declaye S, Dewallef P, Lemort V. Techno-economic survey of organic rankine cycle (ORC) 
systems. Renewable and Sustainable Energy Reviews 2013;22(0):168 -86. doi:10.1016/j.rser.2013.01.028.

[2] Liu BT, Chien KH, Wang CC. Effect of working fluids on organic rankine cycle for waste heat recovery. Energy 2004;29(8):1207 -17. doi:10.1016/j.energy.2004.01.004.

[3] Teng H, Regner G, Cowland C. Waste heat recovery of heavy-duty diesel engines by organic rankine cycle part ii: Working fluids for WHR-ORC. 2007. doi:10.4271/200701-0543.

[4] Wang E, Zhang H, Fan B, Ouyang M, Zhao Y, Mu Q. Study of working fluid selection of organic rankine cycle (ORC) for engine waste heat recovery. Energy 2011;36(5):3406 -18. doi:10.1016/j.energy.2011.03.041.

[5] Kuo CR, Hsu SW, Chang KH, Wang CC. Analysis of a $50 \mathrm{~kW}$ organic Rankine cycle system. Energy 2011;36(10):5877-85. doi:10.1016/j.energy.2011.08.035.

[6] Wang D, Ling X, Peng H, Liu L, Tao L. Efficiency and optimal performance evaluation of organic rankine cycle for low grade waste heat power generation. Energy 2013;50(0):343 -52. doi:10.1016/j.energy.2012.11.010.

[7] Crook A. Profiting from Low Grade Heat: Thermodynamic Cycles for Low-temperature Heat Sources. IEE energy series; Institution of Electrical Engineers; 1994. ISBN 9780852968352. Last accessed July, 2013; URL books.google.dk/books? id=-hcGHMP89EYC.

[8] Larsen U, Pierobon L, Haglind F, Gabrielii C. Design and optimisation of organic rankine cycles for waste heat recovery in marine applications using the principles of natural selection. Energy 2013;55:803-12. doi: 10.1016/j.energy.2013.03.021.

[9] Mathworks Massachusetts US. Matlab R2010b. 2010. Last accessed July, 2013; URL www.mathworks.se.

[10] Lemmon E, Huber M, McLinden M. National Institute of Standards and Technology, Maryland, United States, Standard Reference Database 23 Reference Fluid Thermodynamic and Transport Properties-REFPROP, Software version 9.0. 2010. Last accessed July, 2013; URL www.nist.gov.

[11] Chipperfield A, Fleming PJ, Pohlheim H, Fonseca CM. Genetic Algorithm Toolbox for use with Matlab. Tech. Rep.; Department of Automatic Control and Systems Engineering, University of Sheffield, United Kingdom; Sheffield; 1994. Last accessed July, 2013; URL www. lasc.univ-metz.fr/IMG/pdf/GATBXA0.pdf.

[12] Wang J, Yan Z, Wang M, Li M, Dai Y. Multi-objective optimization of an organic rankine cycle (ORC) for low grade waste heat recovery using evolutionary algorithm. Energy Conversion and Management 2013;71(0):146 -58. doi:10.1016/j.enconman.2013.03.028.

[13] Larsen P. University of Southern Denmark website, Regression and analysis of variance. 2005. Last accessed July, 2013; URL statmaster.sdu.dk/courses/st111/index.html.

[14] Johnson RA, Wichern DW. Applied multivariate statistical analysis. Upper Saddle River, NJ: Pearson; 2007. ISBN 9780135143506.

[15] Thorin E. Comparison of Correlations for Predicting Thermodynamic Properties of AmmoniaWater Mixtures. International Journal of Thermophysics 2000;21(4):853-70. doi:10.1023/A:1006658107014.

[16] Bao J, Zhao L. A review of working fluid and expander selections for organic rankine cycle. Renewable and Sustainable Energy Reviews 2013;24(0):325 -42. doi: 10.1016/j.rser.2013.03.040.

[17] Dai Y, Wang J, Gao L. Parametric optimization and comparative study of organic rankine cycle (ORC) for low grade waste heat recovery. Energy Conversion and Management 2009;50(3):576 -82. doi: 10.1016/j.enconman.2008.10.018.

[18] Walraven D, Laenen B, Dhaeseleer W. Comparison of thermodynamic cycles for power production from lowtemperature geothermal heat sources. Energy Conversion and Management 2013;66(0):220 -33. doi: 10.1016/j.enconman.2012.10.003.

[19] Trapp C. Efficiency Improvement in Precombustion CO2 Removal Units With a Waste Heat Recovery ORC Power Plant. Journal of Engineering for Gas Turbines and Power 2013;135(4):0423111-04231111. doi:10.1115/1.4023121. 